\title{
Correction to: A new approach to select the reliable suppliers for one-shot devices
}

\author{
Meysam Azimian ${ }^{1} \cdot$ Mahdi Karbasian $^{2} \cdot$ Karim Atashgar $^{1} \cdot$ Golam Kabir $^{3}$
}

Published online: 13 March 2021

○ German Academic Society for Production Engineering (WGP) 2021

Correction to: Production Engineering

https://doi.org/10.1007/s11740-021-01032-8

Affiliations of the first three authors corrected through this correction.

Original article corrected.

Publisher's Note Springer Nature remains neutral with regard to jurisdictional claims in published maps and institutional affiliations.

The original article can be found online at https://doi.org/10.1007/ s11740-021-01032-8.

Golam Kabir golam.kabir@uregina.ca

Meysam Azimian meysamazimian@yahoo.com

Mahdi Karbasian mkarbasi@mut-es.ac.ir

Karim Atashgar mkarbasian@yahoo.com

1 Industrial Engineering Department, Maleke-Ashtar University of Technology, Tehran, Iran

2 Industrial Engineering Department, Maleke-Ashtar University of Technology, Isfahan, Iran

3 Industrial Systems Engineering, University of Regina, Regina, SK, Canada 